\title{
APPLICATION OF LIDAR AND OTHER PROFILING TECHNIQUES TO STUDY THE IMPACT THAT SEVERE WEATHER HAZARDS HAVE ON THE NEW YORK CITY BUILT ENVIRONMENT
}

\author{
Mark Arend ${ }^{1}$ *, Mark Campmier ${ }^{1}$, Aris Fernandez ${ }^{1}$, Fred Moshary ${ }^{1}$ \\ ${ }^{1}$ NOAA CREST Center and City College of New York, New York, NY 10031, USA, \\ *marend@ccny.cuny.edu
}

\begin{abstract}
The complexity of urban boundary layer dynamics poses challenges to those responsible for the design and regulation of buildings and structures in the urban environment. Lidar systems in the New York City Metropolitan region have been used extensively to study urban boundary layer dynamics. These systems, in conjunction with other sensing platforms can provide an observatory to perform research and analysis of turbulent and inclement weather patterns of interest to developers and agencies.
\end{abstract}

\section{INTRODUCTION}

Global urbanization inspires the construction of new highly elevated skyscrapers to unprecedented heights while existing buildings age. The concurrence of these newer high rises (including the presence of construction sites) along with the older buildings, causes significant engineering challenges for builders and regulatory agencies who are responsible for considering the impact of these buildings by extreme weather events (e.g. high winds and continued erosion induced by tropical and extra-tropical storms). Characterizing the interaction between urban weather systems, the urban boundary layer and the built environment in a large metropolitan region like New York City can benefit from ground based remote sensing observations (such as lidar) especially when these observations are taken in to consideration with other observing platforms in order to provide a more complete description of the potential risks that are inherent within the complex built environment. The early stages of instrumenting the New York City region with such beneficial assets will be presented and a plan for enhancing the observatory suite to better serve stakeholders will be discussed. Ongoing studies that will involve planning for the optimal enhancement of the observatory will be given.

\section{METHODOLOGY}

The beginnings of a ground based observatory based in the NYC Metro area has been evolving over the years that consists of a Doppler wind lidar system, other ground based wind profilers (including a Radar Wind Profiler), a ceilometer for characterizing cloud and boundary layer heights and a Microwave Radiometer for profiling temperature, water vapor, liquid water content. Fig. 1 below shows the locations of these instruments in the NYC metro area.

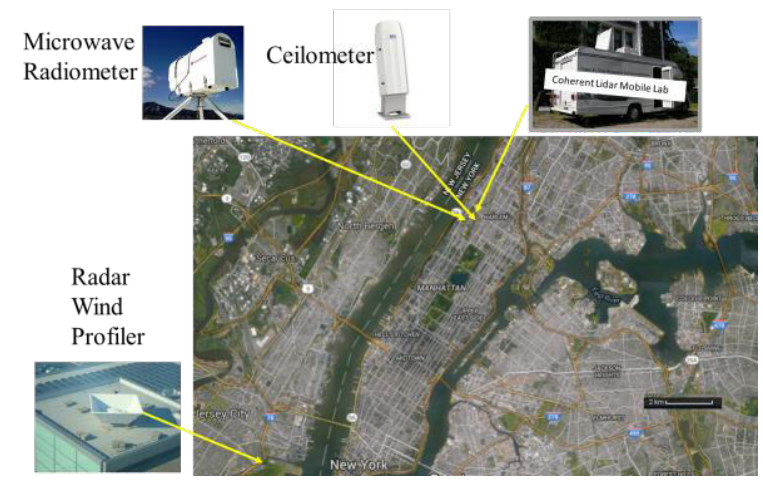

Figure 1 Locations of some of the Optical Remote Sensing Laboratory instruments in the New York Metropolitan area (coherent Doppler lidar, Microwave radiometer, Ceilometer and Radar Wind Profiler)

There have been a number of previous reports that describe the instruments shown in Fig. 1 as well as other atmospheric boundary layer instruments and studies including the construction and evaluation of the Coherent Doppler Lidar (CDL) [1-4]. In addition, a number of previous reports incorporate these instruments (including additional instrumentation) to study the dynamics of the urban atmospheric boundary layer in the NYC metropolitan region with applications to air quality [5,6], wind hazards [7], turbulent boundary layer and stability studies [8-11]. 


\section{RESULTS}

To expand these studies a focus is made on a few case studies namely (1) an event during the summer of 2015 in which a number of the instruments were cooperating and for which the evolution of the boundary layer stability is observed by pointing the CDL vertically and observing the fluctuations of the vertical velocity along with the diurnal cycle of the solar forcing and (2) an extreme wind event during the landfall of Hurricane Sandy on October 29-30, 2012.

\subsection{Observations of diurnal forcings}

Fig. 2 shows a time series of the profiles from the microwave radiometer, $\mathrm{CDL}$ and Ceilometer over the period of two days on July $2^{\text {nd }}$ and July $3^{\text {rd }}$, 2015. The Microwave Radiometer is picking up a clear diurnal signal of the temperature profile during this episode. It should be noted that the synoptic conditions for this event were not necessarily extreme conditions, the temperatures were in the lower 70s (morning) to mid $80 \mathrm{~s}$ (afternoon), and there were weak winds from the NW as a mild cold front passed through and there was low humidity over the few days.

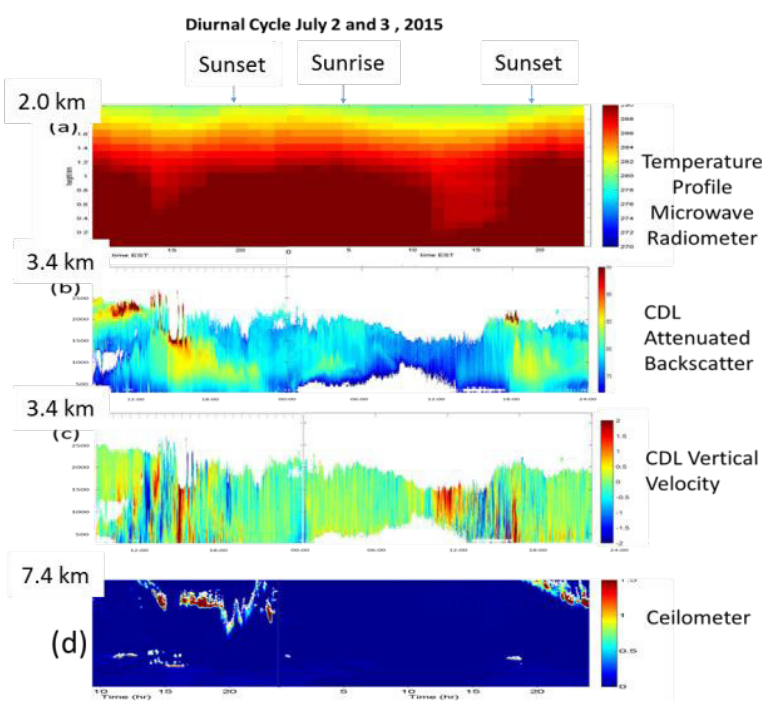

Figure 2. Time series of vertical profiles from the (a) Microwave radiometer, ( $b$ and $c$ ) Coherent Doppler Lidar, and (d) Ceilometer during July 2 and July 3,

2015. The time of Sunset, Sunrise and then Sunset are indicated with arrows above the top plot.

Although the ceilometer is showing the existence of some high level clouds in the evening of July $2^{\text {nd }}$, the diurnal forcing observed in the temperature profiles of the radiometer before sunset on July $2^{\text {nd }}$ appears again on July $3^{\text {rd }}$. These forcings are coincident with a clear signal of vertical fluctuations observed by the CDL before sunset as well as the apparent formation of low level clouds. These observations illustrate the utility of co-operating Doppler lidar systems with other lidars and profilers in order to study the evolution of atmospheric stability. Such studies of the evolution of atmospheric stability become even more important when the synoptic forcing becomes so strong that the winds become hazards to structures as shown in the next example.

\subsection{Wind hazards}

Wind hazards can be studied using ground based remote sensing profilers in order to asses the exposure hazards depending on the type urban landscape. This can provide added value to the commonly accepted standards utilized by Architects, Civil and Construction Engineers as s shown in Fig. 3 below taken from the SEI/ASCE (American Society of Civil Engineers Structural Engineering Institute) handbook [12]. The "three second peak gust wind speed" recorded at NWS stations is typically used as a design guideline when assessing design loads. "Exposure coefficients" are then applied to adjust for height and terrain dependent wind exposure as summarized in Fig. 3.

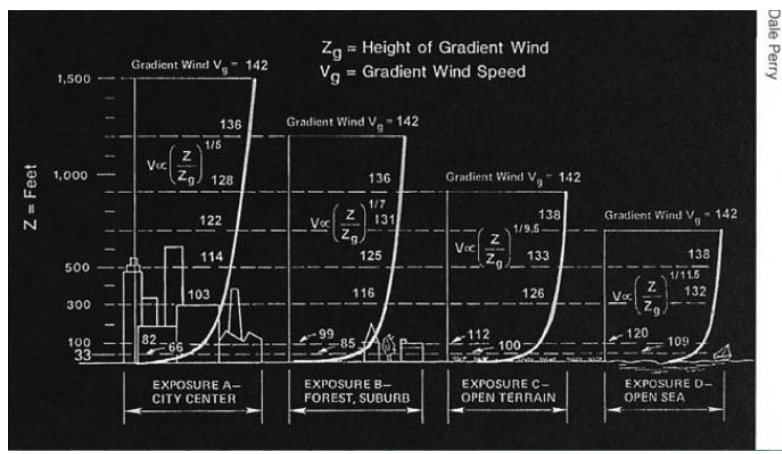

Figure 3. Guidelines from the American Society of Civil Engineers Structural Engineering Institute for assessing the exposure to the built environment for various terrains and heights based on simple assumptions related to surface observations of wind.

As an example on how wind profilers might be useful to better asses the exposure in built environments, a case study during the landfall of Hurricane sandy is studied to point out the utility of profiling winds using ground based remote 
sensing. In this particular example, as illustrated in Fig. 4, a project in which a crane was at risk during the storm presented concerns. The crane collapsed at 2:30 pm EDT (13:30 EST). Also shown in Fig. 4 are the wind barbs from the Radar Wind Profiler. In addition, an anemometer located on the top of a nearby sky scraper recorded the wind speed and direction throughout the period that Hurricane Sandy approached land fell on land. The coincident observations from various profilers as well as surface stations of events like those illustrated in Fig. 4

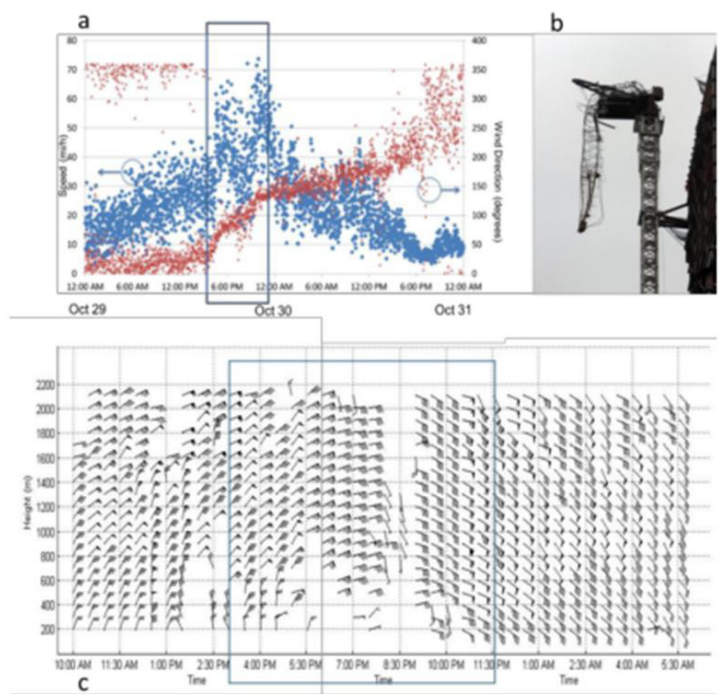

Figure 4. Observations made during the landfall of landfall of Hurricane Sandy. (a) Wind speed (blue) and direction (red) from an anemometer on a weather tower located on top of a building very near to the location of where the crane collapsed (b). (c) Wind barbs from the Radar Wind Profiler (as shown in Fig. 1) are presented indicating the same episode (square boxes indicate the similar time periods.

Another source of observations that can be used in conjunction with the vertical profilers during such extreme events are a collection of weather stations in the NYC metro area. Fig. 5 shows an illustration of the wind speeds over the NY/NJ metropolitan area during the landfall of Hurricane Sandy. Taking all of the observations in to consideration allows for more advanced assessment of the risks that such an extreme event can have not only at the surface but at many vertical levels. Studies such as these can also provide better guidance for entities (both commercial and governmental) who are concerned about setting standards.

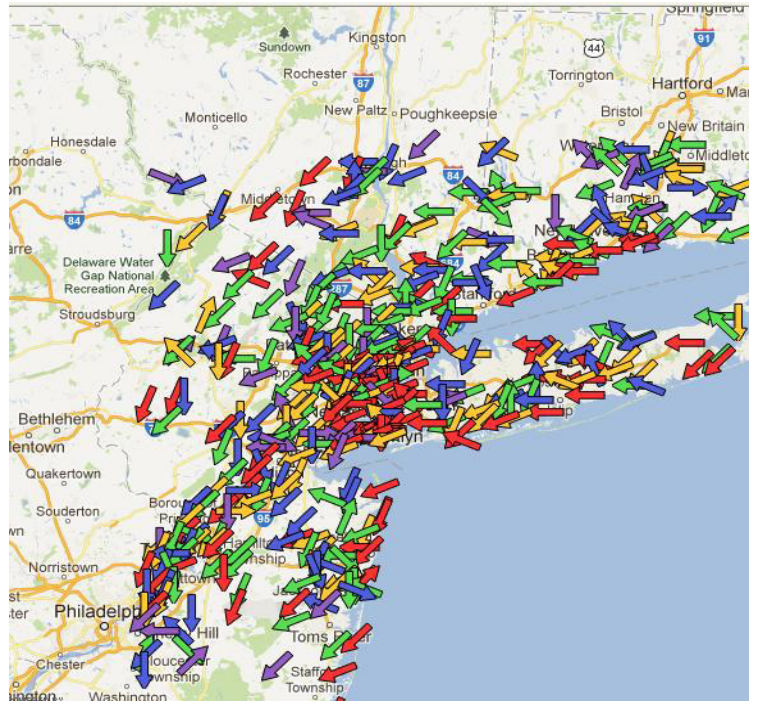

Figure 5. Wind speed and directions as observed by surface weather stations in the NY/NJ Metropolitan region during the landfall of Hurricane Sandy (Oct 29 17:30 EST). Color codes represent wind speed in mph, purple 0-5, blue 5-10, green 10-15, yellow 15-20, red greater than 20.

\section{CONCLUSIONS}

Lidar and other profiling techniques have been used to study the impact that severe weather hazards have in relation to the built environment with a focus on wind hazards and turbulent conditions. In addition, results of an ongoing study funded by the NYC Department of Buildings to evaluate and suggest updates to amend the administrative code of the City of New York, in relation to the effects of wind on certain buildings will be presented.

\section{ACKNOWLEDGEMENTS}

Partial support for this work comes from NOAACREST, the CUNY CREST Institute and the CUNY High Performance Computing Facility

"NOAA-CREST program is funded by NOAA/EPP Grant \# NA11SEC4810004"

"The CUNY HPCC is operated by the College of Staten Island and funded, in part, by grants from the City of New York, State of New York, CUNY Research Foundation, and National Science Foundation Grants CNS-0958379, CNS-0855217 and ACI 1126113."

Any opinions, findings, conclusions, or recommendations expressed in this publication are 
those of the author(s) and do not necessarily reflect the view of the U.S. Department of Commerce National Oceanic and Atmospheric Administration.

\section{References}

[1] Arend, M ; Abdelazim, S., Lopez, M., Moshary, M., 2013: A comparison of two embedded programming techniques for high rep rate coherent Doppler lidars, Proc. SPIE 8731, Laser Radar Technology and Applications XVIII, 87310E (May 28, 2013); doi:10.1117/12.2016018.

[2] Abdelazim, S., Santoro, D., Arend, M. F., Moshary, F., Ahmed, S., 2015: Development and Operational Analysis of an All-Fiber Coherent Doppler Lidar System for Wind Sensing and Aerosol Profiling, Geoscience and Remote Sensing, IEEE Transactions on $\mathbf{5 3}$ (12), 6495-6506.

[3] Abdelazim, S., Santoro, D., Arend, M., Moshary, F., Ahmed, S., 2016: Signal to Noise Ratio Characterization of Coherent Doppler Lidar Backscattered Signals, EPJ Web of Conferences 119 17014, DOI: 10.1051/epjconf/201611917014

[4] Abdelazim, S., Santoro, D., Arend, M., Moshary, F., \& Ahmed, S. 2015: The challenges of implementing and testing two signal processing algorithms for high rep-rate coherent Doppler lidar for wind sensing, Proc. SPIE 9474, Signal Processing, Sensor/Information Fusion, and Target Recognition XXIV, 94741B, DOI:10.1117/12.2176897.

[5] Gan, C., Y. Wu, B. Madhavan, B. Gross, F. Moshary, 2011: Application of active optical sensors to probe the vertical structure of the urban boundary layer and assess anomalies in air quality model PM2.5 forecasts, Atmos. Environ., 45 (37), 6613-6621.

[6] Vladutescu, V., Wu, Y., Gross, B., Moshary, F., Ahmed, S.,Blake, R., Razani, M., 2012: Remote Sensing Instruments used for Measurement and Model Validation of Optical Parameters of Atmospheric Aerosols IEEE Transactions on Instrumentation \& Measurement 61, 1733-1746 (2012)

[7] Arend, M. F., Gutiérrez, E. J., Gonzalez, J. E., Moshary, F., Bornstein, B., Martilli, A., 2014,
Vertical Profiles and Horizontal Distributions of Observed and Modeled Wind and Pressure Fields Over the NYC Metro Area During Superstorm Sandy as a Tool for Understanding Impacts and Risks for a Vertically Built Environment, AMS Annual Meeting, Atlanta GA, 2014

[8] Arend, M., Valerio, I., Neufeld, S., Bishir, B., Wu, Y., Moshary, F., Melecio-Vazquez, D., and Gonzalez, J., 2016: Exploring the Turbulent Urban Boundary by Use of Lidars and Microwave Radiometers, EPJ Web of Conferences $119 \quad 15005$, DOI: 10.1051/epjconf/201611915005

[9] Melecio-Vázquez, D., González-Cruz, J.E., Arend, M., Han, Z., Dempsey, M., Booth, J., Gutierrez, E. and Tongue, J., 2015: New York Metro-Area Boundary Layer Catalogue: Boundary Layer Height and Stability Conditions from Long-Term Observations. 9th International Conference on the Urban Climate jointly with 12th Symposium on the Urban Environment. July 20-24, 2015, Centre de Congres Pierre Baudis, Toulouse, France. URL:http://www.meteo.fr/icuc9/LongAbstracts /nomtm9-2-2991314_a.pdf

[10] Melecio D., and J. Gonzalez, P. Ramamurthy, and M. Arend, 2016: The Structure and Evolution of the Urban Boundary Layer During an Extreme Heat Event, 22nd Symposium on Boundary Layers and Turbulence. June 20-24, 2016, Sheraton Salt Lake City Hotel, Salt Lake City, UT. Conference Presentation. https://ams.confex.com/ams/32AgF22BLT3BG /webprogram/Paper295973.html

[11] Melecio D., J. Gonzalez, P. Ramamurthy, and M. Arend, 2017: Modeling and Observations of the Structure and Evolution of the Urban Boundary Layer of New York City, 97th American Meteorological Society Annual Meeting: 13th Symposium of the Urban Environment. January 22-27, 2017, Washington State Convention Center, Seattle, WA. Conference Presentation.

[12] ASCE. 2010. Minimum Design Loads for Buildings and Other Structures. ASCE/SEI Standard 7-10 